\title{
EFFECT OF BLENDING ON FUEL GAS COMPOSITION OF PYROLYSED PLASTIC WASTES
}

\author{
J. 0. Ejeh $^{1,{ }^{*},}$ B. O. Aderemi ${ }^{2}$ and M. T. Isa ${ }^{3}$ \\ 1, 2, 3 Department of Chemical Engineering, Ahmadu Bello University, Zaria, Kaduna State, NiGERIA. \\ E-mail addresses:1 judejeh@yahoo.com, ${ }^{2}$ boaderemi@abu.edu.ng,3mtisa@abu.edu.ng
}

\begin{abstract}
An investigation into the effects of blending on the gaseous product distribution of plastic wastes was carried out. Waste Low Density Polyethylene (LDPE) and waste High Density Polyethylene (HDPE) samples were subjected to thermal pyrolysis in an electric tubular furnace. First, the effect of heating rate on the volume of the gaseous products was studied. Heating rate values of $22^{\circ} \mathrm{C} / \mathrm{min}, 26^{\circ} \mathrm{C} / \mathrm{min}$ and $32^{\circ} \mathrm{C} / \mathrm{min}$ were used with results showing that a higher heating rate favoured the production of non-condensable gases in HDPE but caused a persistent decrease in LDPE. The investigation into the effects of blending was then carried out at a temperature range of $480{ }^{\circ} \mathrm{C}-600^{\circ} \mathrm{C}$ and heating rate of $22^{\circ} \mathrm{C} / \mathrm{min}$ using blends of $0 \%, 20 \%, 40 \%, 50 \%, 60 \%, 80 \%$ and $100 \%$ LDPE in HDPE. The gaseous product was analysed by gas chromatography and results obtained showed a similarity in hydrocarbon product distribution for both LDPE and HDPE gas products. 100\% LDPE showed a composition of $21.84 \%, 47.39 \%$, 20.78\%, $8.40 \%$, and $1.59 \%$; and $100 \%$ HDPE showed a composition of $18.88 \%, 46.91 \%, 22.89 \%, 9.59 \%$, and $1.73 \%$ for $C_{1}, C_{2}$, $C_{3}, C_{4}$, and $C_{5+}$ hydrocarbon molecules respectively. The presence of LDPE in blends of LDPE-HDPE favoured the production of C1 up to $99 \mathrm{~mol}$. \%.
\end{abstract}

Keywords: pyrolysis, waste plastics, LDPE, HDPE, fuel gas

\section{INTRODUCTION}

There have been growing concerns on the impact of solid wastes on the environment, especially nonbiodegradable wastes. In Nigeria, plastic wastes have been found to be one of the most emitted solid waste as shown in Table $1[1,2]$. Plastics are basically high molecular weight materials derived from petroleum chemicals [3]. They are repeating units of small molecules called monomers [4]. It is one of the most commonly used materials in daily life world over, owing to its light weight, easy shaping and colouring, and poor conduction of heat. However, plastics have a setback of non-biodegradability, and so the need to find a proper way of disposal [3].

Popular means of solid waste disposal have been by landfills and incineration. The use of landfills for plastic waste disposal is not environmental friendly, as plastics do not degrade overtime on burying. Disposal by incineration also leads to the release of toxic and greenhouse gases. A panacea was finally found through years of research efforts, in recycling as an alternative means of plastic waste disposal [5].
Recycling involves reprocessing a material for use as same as the parent material or for any other means [5]. Plastics particularly have proven to be excellent materials for recycling, producing products that are applicable to the textile, automobile, building industry, and others. More recently, the knowledge that plastics are obtained from hydrocarbon raw materials is being harnessed to develop technologies to reverse the process, producing hydrocarbon fuels from waste plastics. Some of such technologies that have been developed are pyrolysis, gasification, liquefaction and monomerization, of which pyrolysis is the most common [6].

Pyrolysis is a cracking process achieved by heating in the absence of air, with or without a catalyst. Products commonly obtained from plastic pyrolysis are noncondensable gases, liquid fuels or waxes, and char, whose components range from simple hydrogen molecules, to aliphatic and aromatic hydrocarbons, saturated and unsaturated, to coke, all depending on the reaction conditions of temperature, residence time, heating rate, reactor type and a host of other factors [3]. 
The liquid fuels obtained are further subjected to distillation and separation techniques to obtain useful fractions with kerosene-like and diesel-like properties. The non-condensable gases on the other hand can be scrubbed, compressed, and put into use as feedstock for petro-chemical industries or used directly as a fuel. The char formed can be used as a carbon adsorbent [3]. The liquid products have been the primary focus for research and production but have been plagued with having low octane number ratings [7].

Several factors have also been observed to affect the nature of the products of pyrolysis. First amongst these is the chemical nature of feedstock. The structure of the plastic feedstock may be classified as linear, branched or cross linked. Increased branching has also been found to reduce the density of the polymer molecule as well as affect the bond energies within the polymers and their relative stabilities [8].

Although, the chemical composition and structure of plastic feed for pyrolysis has a direct influence on the nature of the products, no concrete data has been obtained linking the product type to specific plastic feed type over a specific reacting condition. The second factor is the reaction temperature. It has generally been observed that the higher the temperature, the higher the yield of non-condensable gaseous products and the lower the yield of liquid fuels such as Diesel [9].

Heating rate and residence time has also been known to affect the products of plastic pyrolysis. Inpyrolysis of plastic polymers, residence time, for fast or continuous pyrolysis process, refers to the contact time of the plastic (waste or virgin) on the hot surface in the reactor, or the period from when the feedstock starts to be heated, to the time the products are removed, for a slow or batch pyrolysis process [3]. Other factors include the presence of a catalysts, and reactor type $[3$, 9].

Pyrolysis, being an old technology but yet new in its application to plastics conversion to fuel, has data available in literature, mostly for reaction conditions and the effect of some reaction conditions on the rate of the reaction and nature of the product formed. Gao[3] noted the general effect of temperature, pressure, heating rate, catalyst and residence time on the product distribution during pyrolysis. He successfully pyrolysed polyethylene (PE) (low density polyethylene (LDPE) and high density polyethylene (HDPE)), polypropylene (PP) and polystyrene (PS), thermally and catalytically, establishing their cracking temperature and producing non-condensable gases, liquid/wax and charred products. LDPE, HDPE, PP and PS was also separately pyrolysedto liquid products noting the unique product distribution for each plastic type [10]. It was also observed that mixing, although done unsystematically, of the waste plastics gave a higher yield of liquid products. The effect of catalysts was also been investigated with results showing and increased overall liquid product formed at a reduced cracking temperature [3, 9]. Ademiluyi and Adebayo [11] investigated the nature of fuel gases produced from the pyrolysis of waste polyethylene at low and high temperatures. Gaseous products obtained were ethane, propane, propylene, (normal and iso-) butane at varying proportions with temperatures. Amidst the wealth of research that has been conducted on pyrolysis of plastics, either virgin or waste, little work has been able to systematically relate combination of different types of waste plastic material feed to the nature of products formed.

This study was aimed at the use of waste LDPE and HDPE; preparing the samples for pyrolysis, investigating the effect of heating rates on the volume of gaseous product, pyrolysing the waste plastic samples separately and as mixtures of the waste plastic types, and finally analysing the nature of the gaseous products from each pyrolysis run.

\section{MATERIALS AND METHOD}

The major materials used in the course of this research were High Density Polyethylene (HDPE) and Low Density Polyethylene (LDPE). The samples of waste plastic types were sourced from waste dump sites within Zaria, Kaduna State, North-western Nigeria and sorted out by type: LDPE and HDPE. The waste samples of LDPE and HDPE were washed with a detergent, dried in air and cut into smaller sizes with a pair of scissors, and are as shown in Plate 1.

Table 1: Percentage Composition of Municipal Waste in Popular Cities in Nigeria, Nabegu [5]

\begin{tabular}{lccccccc}
\hline & Nsukka & Lagos & Makurdi & Kano & Onitsha & Ibadan & Maiduguri \\
\hline Putrescribe & 56 & 56 & 52.2 & 43.0 & 30.7 & 76 & 25.8 \\
Plastic & 8.4 & 4 & 8.2 & 4.0 & 9.2 & 4.0 & 18.1 \\
Paper & 13.8 & 14.0 & 12.3 & 17.0 & 23.1 & 6.6 & 7.5 \\
Textile & 3.1 & - & 2.5 & 7.0 & 6.2 & 1.4 & 3.9 \\
Metal & 6.8 & 4.0 & 7.1 & 5.0 & 6.2 & 2.5 & 9.1 \\
Glass & 2.5 & 3.0 & 3.6 & 2.0 & 9.2 & 0.6 & 4.3 \\
Others & 9.4 & 19.0 & 14.0 & 22.0 & 15.4 & 8.9 & 31.3 \\
\hline
\end{tabular}




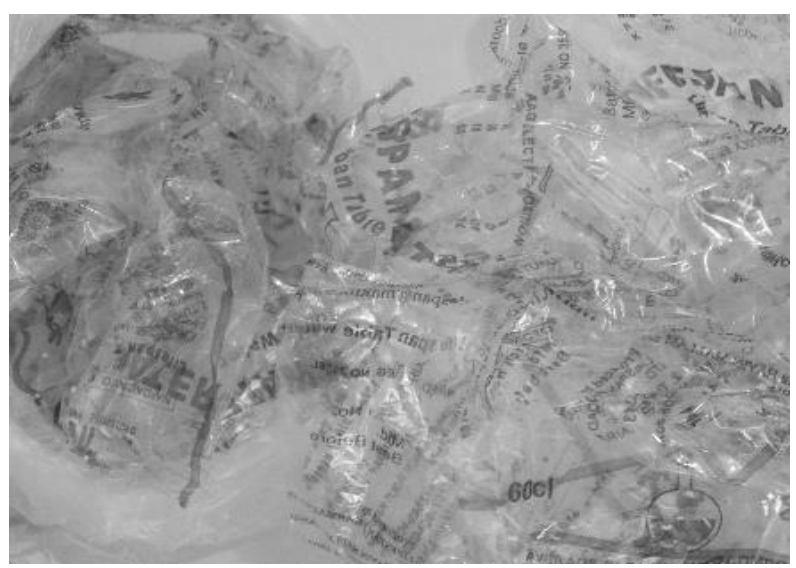

(a)

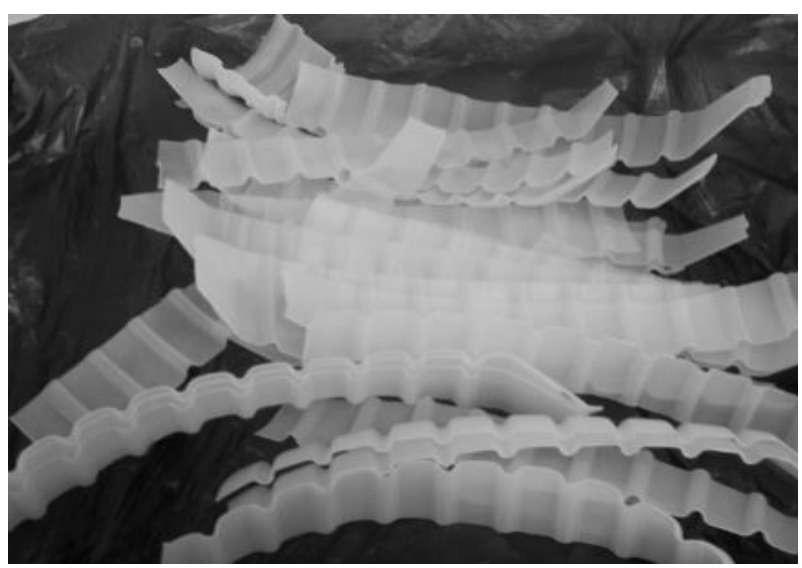

(b)

Plate 1: Samples of Waste (a) LDPE, (b) HDPE

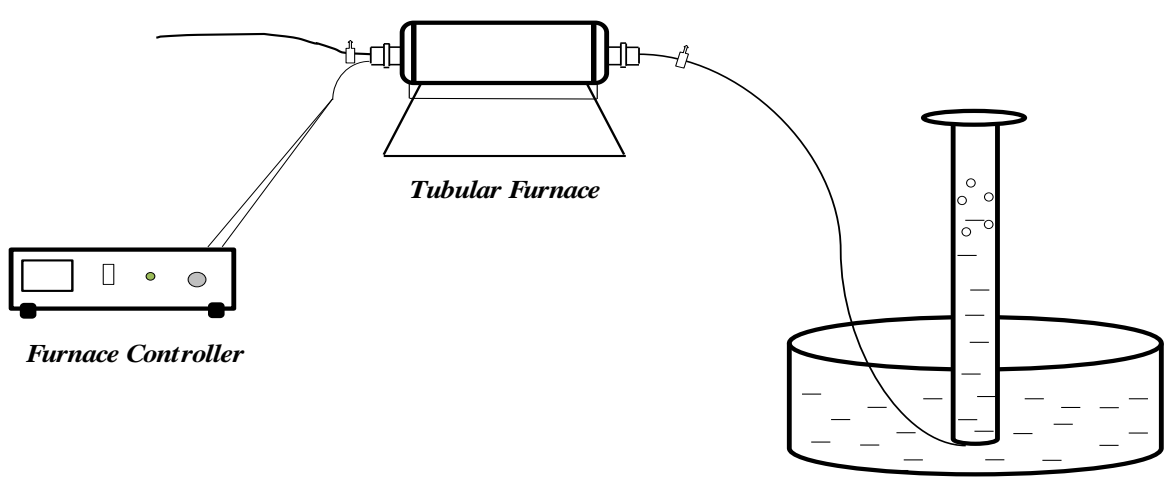

Gas over wat er Collection

Figure 1: Schematic Drawing of Pyrolysis Apparatus (Effect of Heating Rate)

Thermal pyrolysis was adopted for this investigation using a semi-batch reactor in a Hoskins Muffled Electric Furnace (FD303A). A temperature range of $480^{\circ} \mathrm{C}-$ $600^{\circ} \mathrm{C}$ and a heating rate of $22^{\circ} \mathrm{C} / \mathrm{min}$ were used for each sample for maximum gas production. Heating rate conditions were achieved with the help of a Thermolyne furnace controller (CP12910) connected to the electric furnace while weigh measurements were taken using an Ohaus electronic weighing scale (AV264).

For the investigation into the effect of heating rates, approximately $1 \mathrm{~g}$ of each waste plastic type was used in each pyrolysis run. The system was set up as shown in Figure 1. The gaseous products were collected over water and measured off a measuring cylinder.

Approximately $1 \mathrm{~g}$ of the waste LDPE sample was placed inside the reactor and fitted into the tubular furnace. The furnace was then switched on and left to build up in temperature. Readings of temperature and the volume of gaseous product collected were recorded over time for each set of heating rate value for the initial stated temperature range.

For the investigation into the chemical composition of the gaseous product, approximately $3 \mathrm{~g}$ of waste plastic was used in each pyrolysis run. The system was set up as shown in Plate 2. The gas collector was an empty medical intravenous fluid plastic bag of which gaseous contents were held in place with the aid of Hoffman clips, plastic stoppers and paper tapes. The gas collector was evacuated of air with suction pumps before each use. Proportions of 0\%, 20\%, 40\%, 50\%, $60 \%$ and $80 \%$ by weight of the different waste plastic types was used.

Approximately $3 \mathrm{~g}$ of the waste LDPE sample was placed inside the reactor and fitted into the tubular furnace. The furnace was then switched on and left to build up in temperature. As the temperature reached $150^{\circ} \mathrm{C}$, the reactor was then sealed with the aid of Hoffman clips. This was done to allow for purging of the system. At a temperature of $480^{\circ} \mathrm{C}$, the clip on the side of the gas collector was opened to allow for collection of the gaseous products. Collection was continued until a maximum temperature of $600^{\circ} \mathrm{C}$. The gas collector was then sealed off with the aid of its stopper, a Hoffman clip and paper tape, after which it was taken for analysis with a Hitachi Gas Chromatograph.

The same procedure was repeated for waste HDPE. Subsequently, samples containing 20, 40, 50, 60 and 80 
percent of LDPE in HDPE by weight were pyrolysed and analysed by gas chromatography.

The products obtained from each semi-batch run were analysed using a Hitachi Gas Chromatograph (GC) in order to ascertain the products, particularly, the types of hydrocarbon molecules present namely, $\mathrm{C}_{1}, \mathrm{C}_{2}, \mathrm{C}_{3}, \mathrm{C}_{4}$, $\mathrm{C}_{5+}$.

For the analysis of $\mathrm{C}_{1}, \mathrm{C}_{2}, \mathrm{C}_{3}, \mathrm{C}_{4}, \mathrm{C}_{5+}$, the Hitachi 263-50 gas chromatograph equipment was turned on until it achieved the required conditions of a column temperature of $40^{\circ} \mathrm{C}$, detector temperature of $100^{\circ} \mathrm{C}$ and injection section temperature of $30^{\circ} \mathrm{C}$ after which the gas collector was attached to the chromatograph, introduced into it and then the recorder started. The column used helium as its carrier gas. The retention times as well as the nature of the peaks for each component found where recorded and drawn by the recorder. The chromatograph was run for a maximum of ten minutes and the result analysed based on known standards of $\mathrm{C}_{1}, \mathrm{C}_{2}, \mathrm{C}_{3}, \mathrm{C}_{4}, \mathrm{C}_{5+}$.

\section{RESULTS AND DISCUSSION}

\subsection{Effect of Heating Rate on LDPE Pyrolysis}

The effect of heating rate on the volume of gaseous products obtained was studied for LDPE. Heating rates of 22,26 and $32^{\circ} \mathrm{C} / \mathrm{min}$ were used and the results are graphically shown in Figure 2.

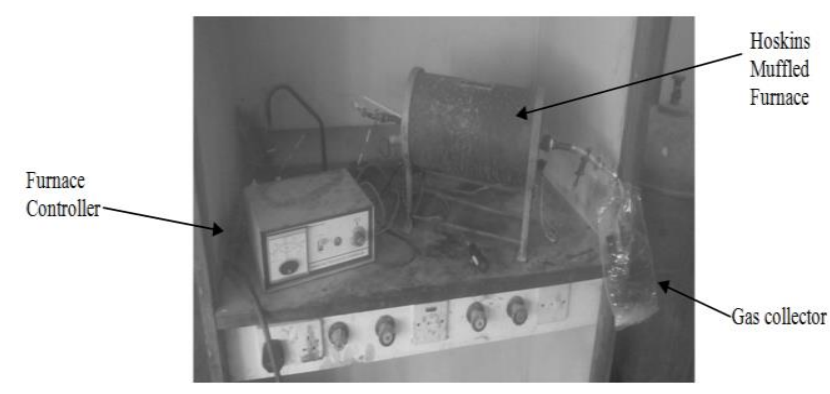

Plate 2: Experimental Setup for pyrolysis of waste PE plastic mixtures

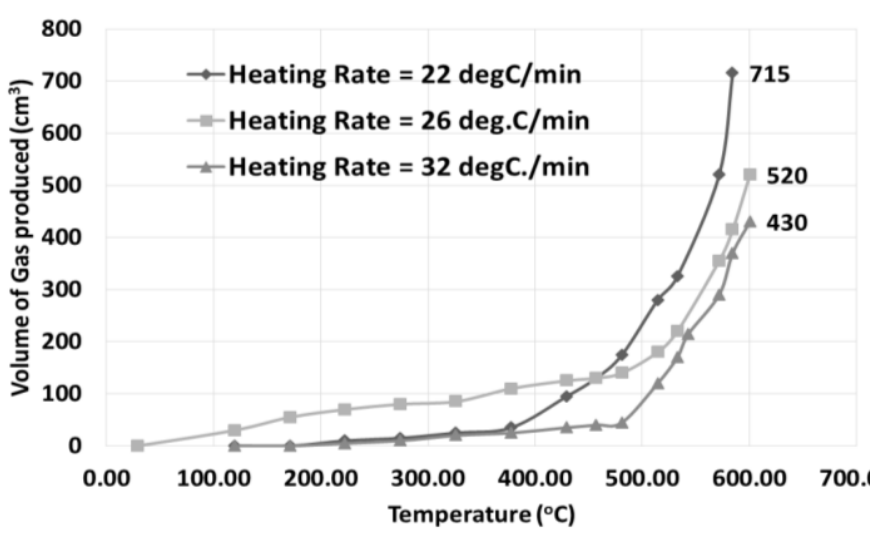

Figure 2: Effect of Heating Rate on Volume of Gas Products for LDPE Samples
It had been noted by Gao [3] and Zorriqueta [9] that an increase in temperature and heating rate favoured the production of non-condensable gases with appreciable gas formation starting above $450^{\circ} \mathrm{C}$ and $20^{\circ} \mathrm{C} / \mathrm{min}$. This observation applied to heating rates of 26 and 32 ${ }^{\circ} \mathrm{C} / \mathrm{min}$ with appreciable gas formation starting at $480^{\circ} \mathrm{C}$. For a heating rate of $22^{\circ} \mathrm{C} / \mathrm{min}$, appreciable gas formation started at $380^{\circ} \mathrm{C}$.

Overall, a higher heating rate led to a relatively lower volume of non-condensable gas products. Heating rates of 22,26 and $32{ }^{\circ} \mathrm{C} / \mathrm{min}$ produced gases totalling $715 \mathrm{~cm}^{3}, 520 \mathrm{~cm}^{3}, 430 \mathrm{~cm}^{3}$ respectively. This is attributed to the fact that LDPE polymer molecules are branched. The bond energies possessed by the main stem of the polymer chain are relatively higher than that of the branches. The bond dissociation energy of C$\mathrm{C}$ and $\mathrm{C}-\mathrm{H}$ bonds are $347 \mathrm{~kJ} / \mathrm{mol}$ and $413 \mathrm{~kJ} / \mathrm{mol}$ respectively [12]. As such, cracking of the $\mathrm{C}$-C bonds requires lower energy and thus, is a more probable initiation step for the pyrolysis process, and as LDPE molecules contains more $\mathrm{C}-\mathrm{C}$ than $\mathrm{C}-\mathrm{H}$ bonds as compared to HDPE, LDPE will favour the formation of low molecular weight hydrocarbon components. Such hydrocarbon components are subject to secondary cracking processes owing to the higher heating rates and temperatures that the reaction condition avails, leading to a reduction in the volume of the gaseous products for LDPE.

As such, a heating rate of about $22{ }^{\circ} \mathrm{C} / \mathrm{min}$ is recommended for gas production from LDPE as higher heating rates will lead to lower non-condensable gas formation.

\subsection{Effect of Heating Rate on HPDE Pyrolysis}

The effect of heating rate on the volume of gaseous products obtained was studied for HDPE. Heating rates of 22,26 and $32^{\circ} \mathrm{C} / \mathrm{min}$ were used and the results are shown graphically in Figure 3.

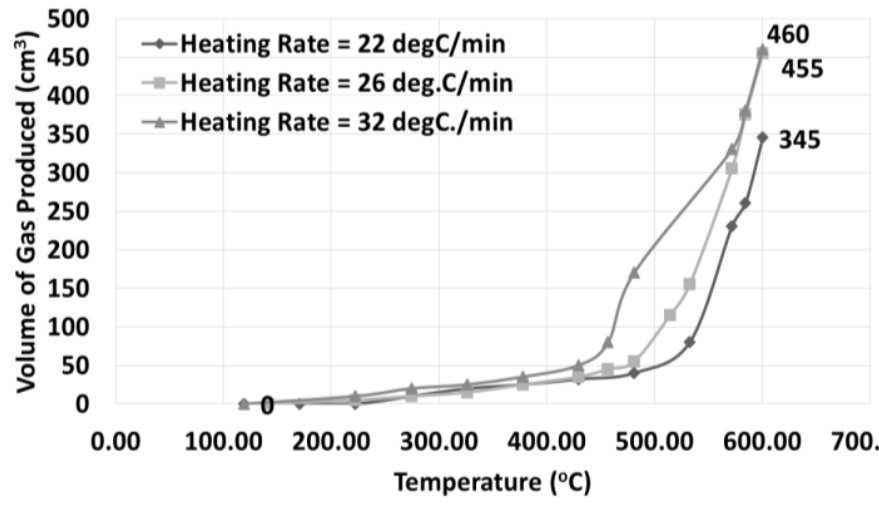

Figure 3: Effect of Heating Rate on the Volume of Gas Products for HPDE Samples

Vol. 36, No. 4, October 2017 
HDPE showed a similar trend to LDPE, as appreciable gas formation occurred above $460^{\circ} \mathrm{C}$. This is in agreement with the observation of Gao [3]. Also, higher heating rates favoured the formation of gaseous products.

Heating rates of 22,26 and $32{ }^{\circ} \mathrm{C} / \mathrm{min}$ produced gases of $345 \mathrm{~cm}^{3}, 455 \mathrm{~cm}^{3}$, and $460 \mathrm{~cm}^{3}$ volumes respectively. This can be attributed to the fact that higher heating rates favour secondary pyrolysis process where heavy hydrocarbon molecules in the liquid and waxy components are further cracked to lighter hydrocarbons.

As compared to LDPE, HDPE showed a lower volume of gaseous products formed. Although LDPE and HDPE have the same chemical components, the difference in the structure of the two molecules accounts for this observation. As observed from Figure 2, the straight chain nature of HDPE (as opposed to the presence of branches in LDPE) presents a lower number of short chain hydrocarbon branches along the main polymer stem, and also a lower number of $\mathrm{C}-\mathrm{C}$ to $\mathrm{C}-\mathrm{H}$ bonds. This makes a higher percentage of the random scission initiation step to occur along the main stem of the HDPE polymer producing radicals with high molecular weight hydrocarbons as compared to LDPE. Surplus energy present due to high heating rates will thus favour further cracking to lower molecular weight hydrocarbons.

\subsection{Gas Chromatography Analysis}

Figures 4 shows a typical Gas Chromatogram for $\mathrm{C}_{1}-$ $\mathrm{C}_{5+}$ components in the gaseous product obtained from pyrolysis. Gas Chromatograms for each of the waste plastic mixture pyrolysed were obtained.

From Figure 4 peaks at retention time of 2.3 minutes indicate the presence of $\mathrm{C}_{1}$ component. $\mathrm{C}_{2}, \mathrm{C}_{3}$, and $\mathrm{C}_{4}$ components have retention times of $2.4,2.8-2.9$ and 4.0 - 4.1 minutes respectively, and $\mathrm{C}_{5+}$ components showed peaks beyond 4.2 minutes.

The product distribution of 100\% LDPE and 100\% HDPE samples as noted in the boundaries in Table 3 are relatively the same. $100 \%$ LDPE showed a composition of $21.84 \%, 47.39 \%, 20.78 \%, 8.40 \%$, and $1.59 \%$ and $100 \%$ HDPE showed a composition of $18.88 \%, 46.91 \%, 22.89 \%, 9.59 \%$, and $1.73 \%$ for $\mathrm{C}_{1}, \mathrm{C}_{2}$, $\mathrm{C}_{3}, \mathrm{C}_{4}$, and $\mathrm{C}_{5+}$ respectively. This is comparable to results obtained by Gao[3] for non-condensable gases obtained from LDPE pyrolysis having 12.2\%, 32\%, $34.7 \%$ and $21.1 \%$ of $\mathrm{C}_{1}, \mathrm{C}_{2}, \mathrm{C}_{3}$ and $\mathrm{C}_{4}$ respectively. This is attributed to their similar chemical makeup, although LDPE showed a relatively higher composition of lighter components $\left(\mathrm{C}_{1}\right.$ and $\left.\mathrm{C}_{2}\right)$, owing to branching within the LDPE molecule.

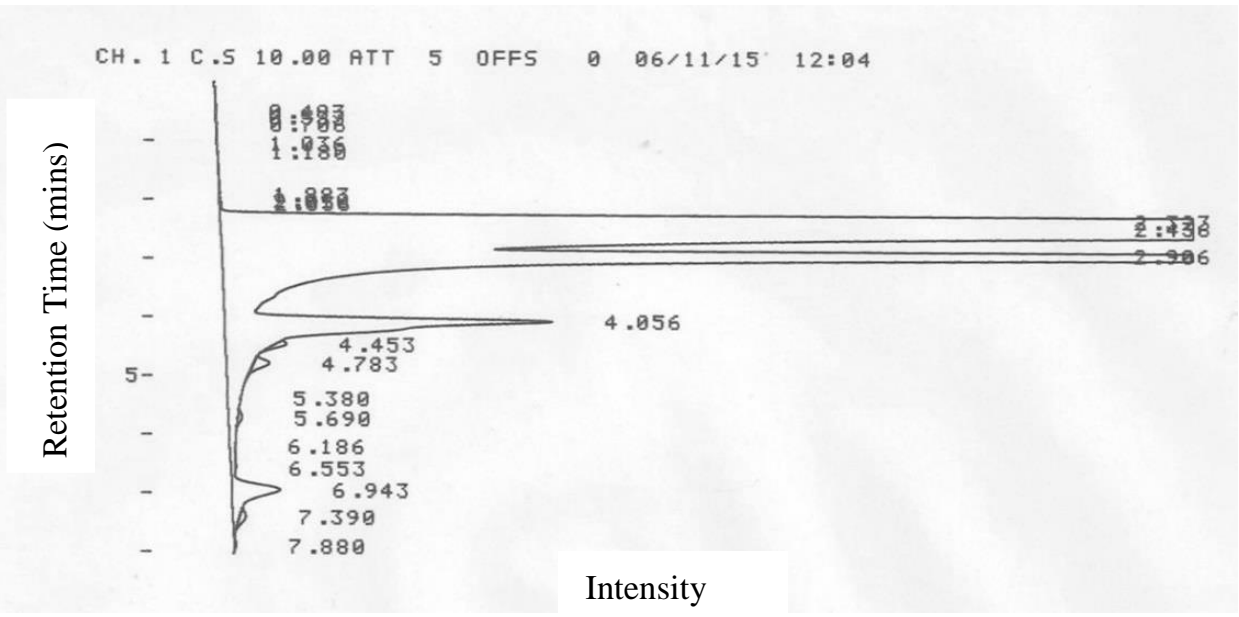

Figure 4: Typical Gas Chromatogram for Hydrocarbon Components Present $\left(C_{1}-C_{5}\right)$

Table 3: Summary of Relative Amounts of Hydrocarbons In Gas Products

\begin{tabular}{cccccccc}
\hline $\begin{array}{l}\text { S/N } \\
\text { o. }\end{array}$ & $\begin{array}{c}\text { LPDE } \\
(\%)\end{array}$ & $\begin{array}{c}\mathrm{HDPE} \\
(\%)\end{array}$ & $\begin{array}{c}\mathrm{C}_{1} \\
(\text { mole\%) }\end{array}$ & $\begin{array}{c}\mathrm{C}_{2} \\
(\text { mole\%) }\end{array}$ & $\begin{array}{c}\mathrm{C}_{3} \\
(\text { mole\%) }\end{array}$ & $\begin{array}{c}\mathrm{C}_{4} \\
(\text { mole } \%)\end{array}$ & C5 $_{5}$ or Liquid (mole \%) \\
\hline 1 & 0 & 100 & 18.88 & 46.91 & 22.89 & 9.59 & 1.73 \\
2 & 20 & 80 & 25.81 & 46.65 & 19.87 & 6.39 & 1.28 \\
3 & 40 & 60 & 28.60 & 47.83 & 17.63 & 5.05 & 0.89 \\
4 & 50 & 50 & 97.32 & 0.00 & 1.61 & 0.38 & 0.68 \\
5 & 60 & 40 & 89.94 & 3.62 & 4.71 & 1.30 & 0.43 \\
6 & 80 & 20 & 99.77 & 0.00 & 0.00 & 0.00 & 0.23 \\
7 & 100 & 0 & 21.84 & 47.39 & 20.78 & 8.40 & 1.59 \\
\hline
\end{tabular}


It was observed that an increase in the amount of LDPE favoured the formation of $\mathrm{C}_{1}$ component. This is consistent with literature as explained in Gao [3], Beyler and Hirschler [8], and Panda [12]. The presence and nature of LDPE molecules favours the production of smaller hydrocarbon molecules at the initiation step of the pyrolysis reaction. This is because the branches within LDPE molecules are of a shorter chain length than the main straight stem of the molecule, and as the dissociation energy for branches are lower than for the main stem, the initiation step -was probable to occur at the point of branches. It is further shown in Figure 3 that the relative stabilities of bond types vary. The first class in Figure 3 predominates in HDPE and the third in LDPE, as such the initiation step is more favourable to occur with LDPE molecules and at sites of branches. This is as opposed to HDPE in which pyrolysis initiation occurs randomly along the molecule leading to a wider range of carbon lengths. As such, a higher amount of LDPE will favour shorter chain hydrocarbons production.

Gas Chromatograms for the analysis of oxygen, nitrogen, carbon monoxide and carbon dioxide present in the pyrolysed gas samples were also obtained. Chromatograms for all samples analysed indicated that carbon monoxide and carbon dioxide where absent. Only peaks at retention times of 1.0 and 1.2 representing oxygen and nitrogen, indications of air, were detected. Other peaks were indications of impurities encountered during the pyrolysis process. The absence of carbon dioxide and carbon monoxide in the gas product is consistent with expectations [3], and also with literature data, as the pyrolysis process was carried out in a reduced oxygen environment.

\section{CONCLUSION}

Higher heating rates were found to favour the production of non-condensable gases for waste HDPE but not for waste LDPE. This was attributed to the difference in the structure of the two polymers. The non-condensable gases obtained from the pyrolysis of waste HDPE and LDPE consisted mainly of $\mathrm{C}_{1}, \mathrm{C}_{2}, \mathrm{C}_{3}, \mathrm{C}_{4}$, and traces of $\mathrm{C}_{5+}$ type hydrocarbons with product distribution of pyrolysed 100\% LDPE and 100\% HDPE being similar, although LDPE had a higher amount of $\mathrm{C}_{1}$ and $\mathrm{C}_{2}$. Also, the presence of LDPE in the pyrolysis of waste LDPE-HDPE mixtures favoured the formation of $\mathrm{C}_{1}$ hydrocarbons.

\section{ACKNOWLEDGMENT}

We wish to acknowledge the Petroleum Technology Development Fund, Ahmadu Bello University, Zaria, and the Kaduna Refining and Petrochemical Company, Kaduna State for providing access to equipment to carry out this research.

\section{REFERENCES}

[1] Nabegu, B. A. "An Analysis of Municipal Solid Waste in Kano Metropolis, Nigeria". Journal of Human Ecology, 31(2), Pp 111-119, 2010.

[2] Ayuba, A. K., Manaf, A. L., Sabrina, H. A. and Azmin, W. N. S. "Current Status of Municipal Solid Waste Management Practice in FCT Abuja". Research Journal of Environmental and Earth Sciences, Vol. 5(6), pp 295-304, 2013.

[3] Gao, F. "Pyrolysis of Waste Plastics into Fuels". University of Canterbury. Unpublished Ph.D thesis, pp 12-97, 122-132, 2010.

[4] Ebewele, R. O. "Polymer Science and Technology". CRC Press LLC, New York, U.S.A, pp 30, 2000.

[5] Nabegu, B. A. "Solid Waste and Its Implications for Climate Change in Nigeria". Journal of Human Ecology, 34(2), pp 67-73. 2011.

[6] Plastic Waste Management Institute (PWMI), " $A n$ Introduction to Plastic Recycling". Plastic Waste Management Institute, Japan, pp 10-24, 2009.

[7] Ofoma, I. "Catalytic Pyrolysis of Polyolefins". Unpublished Thesis. School of Chemical and Bimolecular Engineering. Georgia Institute of Technology, U.S.A, pp 8-9. 2006.

[8] Beyler, L. C., and Hirschler, M. M. "Thermal Decomposition of Polymers". SFPE handbook of fire protection engineering 2, pp 1-110 - 1-131. 2012.

[9] Zorriqueta, J. N. I. "Pyrolysis of Polypropylene by Ziegler-Natta Catalysts". Universitat Hamburg. Unpublished Ph.D thesis, pp 5-28, 93-95, 2006.

[10] Sarker M. and Rashid, M. M. "First Simple and Easy Process of Thermal Degrading Municipal Waste Plastics into Fuel Resource". IOSR Journal of Engineering, Volume 2 (9), pp 38-49, 2012.

[11] Ademiluyi, T. and Adebayo, T. A. "Fuel Gases from pyrolysis of waste Polyethylene sachets". Journal of Applied Science and Environmental Management. Volume 11 (2), pp 21- 26, 2007.

[12] Panda, A. K. "Studies on Process Optimization for Production of Liquid Fuels from Waste Plastics". National Institute of Technology, Rourkela. Unpublished Ph.D thesis, pp 57-63. 2011. 